\title{
Accountability and disposal: visual impairment and the museum Kevin Hetherington*
} University of Lancaster

\section{Introduction}

Sarah, now in her late 70s, has been visually impaired since she was a child. An avid visitor to museums for many years, she has now become something of an expert on what she calls 'the touch scene' within the arts in Britain. This touch scene, as it is known, is associated with the tactile exhibitions and facilities that can be found in museums. Within museums this is often aimed at three different audiences, children on school visits, outreach work with elderly people and facilities for visually impaired visitors. As well as visiting museums and galleries all around Britain for her own pleasure, Sarah also advises groups like the charity for the visually impaired, the Royal National Institute for the Blind (RNIB). She also acts as an informal consultant to many museum education officers and local support groups run for and by the visually impaired, on how to provide access to museums and their exhibits for those who are unsighted or partially sighted.

Her enthusiasm has not always met with support from people in the museum sector. Until very recently, it was the case that most museums in Britain had a problem with the idea of disabled access and especially with access for those with visual impairments. More precisely they saw this as a problem. This attitude is beginning to change. While the rights of disabled people are acknowledged, the main reasons for change arise from the fact that disabled access is coming to be seen as a resource within the museum sector. For example, while the passing in 1995 of the Disability Discrimination Act in Britain has had some impact on the museum sector, it is the introduction of a National Lottery in 1994 that has been of more significance. The former now makes it illegal to for institutions like museums to discriminate against disabled people, but the latter has provided major funding for the arts in Britain and issues of access have been prominently associated with the allocation of that money.

Even so, it remains the case that many museums still have a problem with the idea of access through senses other than sight, and especially with that of touch - something that is very important for the visually impaired visitor. From the point of view of museums touching and handling create risk and are sources of worry in relation to the conservation of objects. Not only can exhibits get dropped but their handling over an extended period may lead to the corrosion materials by the acids in the sweat that a person leaves behind on an object. ${ }^{1}$ In the past museums could politely ignore that problem by denying access through touch to those who were not able-bodied. More often some kind of ad-hoc arrangement might have been made to 'show someone around'. But these recent developments have changed all that.

Sarah remembers her first visit to a touch tour put on by the Tate Gallery in London in 1976. Well ahead of its time, this event pioneered the idea in Britain of providing a temporary exhibition for the visually impaired in which pre-selected objects were available to be handled by those who were unable to see. The amount of knowledge then available to museums staging such exhibitions was rudimentary and some elementary mistakes were made. For example, visually impaired people were not allowed to take sighted friends into the exhibition with them as guides. Sarah remembers stumbling around unaided, not being able to find her way through the space let alone being able to find the objects to be handled.

Developments really began in this area in the 1980s. 1981 was designated by the United Nations as International Year of Disabled Persons. In the 1980s there was a Carnegie Trust funded report into disabled access to the arts (Carnegie United Kingdom Trust 1985), as well as a follow-up report on the outcomes of this report. ${ }^{2}$ However, it was not until around 1990 that a few museums in Britain began to take the issue of disabled access seriously. Before then the most that any museum might have done is provide an accessible toilet, put in place a couple of wheelchair ramps and in rare instances, have display signs printed in a large font. By 2003, all of these facilities have become much more common, though it is still 
rare for anything more than this to be provided as a matter of course - except as the outcome of a lottery funding initiative in which an access audit is mandatory.

The first permanent touch tours in a British museum were those designed by Ann Pearson for the Egyptian and Graeco-Roman sculpture galleries in The British Museum. These were introduced in 1990 and consisted of a number of Braille/large print signs attached to certain sculptures in each of these galleries and indicating that visually impaired people could touch these particular pieces. Accompanying audio and large print guides were also made available on request from the main desk.

In 1998 I visited the Graeco-Roman Gallery with Sarah who had visited the Gallery many times before and who now acted as my guide on the touch tour. Sighted people, including accompanying persons, were not allowed to touch the designated sculptures and no-one was allowed to touch any of those not designated for touching. The normal procedure for making this touch tour was for the visitor to inform the museum in advance of the visit of their expected time of arrival. If a person was arriving unaccompanied, a museum guide could be provided as long as sufficient advance notice was given.

Sarah went around the gallery touching the sculptures and describing her experiences to me. In part, she was engaged in an act of identification, establishing for herself what each of the sculptures represented. But she was also fascinated by what she called 'the feel' and how it connected with her. The textures of the different kinds of stone that had been used and the variations in temperature were all equally important. As someone skilled in touch and reflexively knowledgeable about it, both as an everyday practice and as a practice associated with museum objects, she told me that she was sensitive to the texture of materials in varying ways depending on how she touched them, which hand she used, whether she made broad sweeping movements with her hands, or more local, detailed investigations with her fingertips. What she found she then also related to experience, mood, feelings and so on.

Sarah was engaged in a series of acts of embodied perception. The knowledge she sought was proximal and motile, in many ways more sensitive to the intricacies of the local than the more distal ways of knowing that we tend to associate with representation and sight. Access by touch meant much more to Sarah than the opportunity for identification or experience of an object as representative of some type or class of museum artefact. Proximal knowledge, not always easily communicated, implies a highly personal and often nonrepresentational form of understanding. Above all it suggests a performative approach to issues of understanding and a blurring of the boundaries between the body and the object being handled. Our embodied experiences rely, usually in a tacit way, on the creation of proximal forms of knowledge. Touch is one source of such knowledge (Jospovici 1996, Turner 1992). Those of us who are sighted often miss this. Touching a lover or holding our children are probably as close as we often get to consciously recognizing this power of touch (Jospovici 1996). The intimacy of touch puts the body in place of the eye as a source of recognition and understanding but it does so without necessarily trying to achieve some representational outcome. Museums often miss this and it is not surprising given the overwhelming prominence that the visual and visual culture has played in their history (Lyotard 1996). Proximal knowledge - intimate handling in this case - has always been the sole privilege of the curator in the museum context in the past.

The relationship between sight and representation in most western cultures tends to bias our understanding towards more distal forms of knowledge. My visit with Sarah suggested to me questions about different forms of knowledge, their representational economies, and the ways in which we are interpellated as subjects by our relations with materials arranged within social spaces (in this case the museum) (Althussser 1971). In this paper, I want to explore some of these issues and the questions they pose (see also Hetherington 2000; 2002). I want to suggest that this distinction between distal and proximal forms of knowledge might be useful for addressing issues of access and disablement in the context of museums and other sites of public culture.

The idea of distal knowledge implies general understanding, knowledge at a distance or the big picture; it is rather like what Donna Haraway calls the 'God trick' (Haraway 1991). That distance is established by representational practice and is concerned with an ontology of being in which the 'thing' being known is assumed to be in a stable and finished state. As 


\section{Cooper and Law suggest,}

Distal thinking privileges results and outcomes, the 'finished' things or objects of thought and action. It privileges the ready-made. So the distal is what is preconceived, what appears already constituted and known, what is simplified; distilled.... The distal is constituted by action at a distance... stresses boundaries and separation, distinctness and clarity, hierarchy and order (Cooper and Law 1995:239)

Involving a distinctly 'Euclidean' representational economy, distal knowledge seeks to show the world through a denoted set of stable relations. The proximal, however, implies something else. Fluidity, process and becoming - proximal knowledge is more local, specific and uncertain. Cooper and Law again,

Proximal thinking deals in the continuous and the 'unfinished'; it is what is forever approached but never attained, it is what is approximated but never fully realized. The proximal is always partial and precarious, forever fated to repeat itself in an effort to reach (but never attain) completion.... The proximal manifests implication and complicity, and hence symmetry, equivalence and equivocality (Cooper and Law 1995:239)

Here the issues become ones of connotation rather than denotation and of a less Euclidean and far more topologically complex representational economy. ${ }^{3}$ Indeed, given the propensity of representation to provide distal knowledge, we might say that proximal knowledge is not necessarily representational at all, rather it is performative, multiple, and heterogeneous in its outcomes. It can also be embodied in ways that do not necessarily have to involve seeing.

It would be overly simplistic to suggest that the sense of sight always promotes distal knowledge while touch is always more proximal. While touch can be sensitive and exploratory, along with sight, it can also be a source of violation - a way of knowing or objectifying, a form of harassment that is intrusive and unwelcome. Indeed, this would be how many museum curators would contemplate the proximity of the hand in relation to some of the objects in their collections. But not so the visually impaired visitor for whom it is not being able to touch that is often experienced as a violation. The issues surrounding touch are inevitably cultural and historical rather than biological. And they are also highly contextual. However, the representational and the non-representational do have some correlation with these different forms of knowledge and there is certainly more of an affinity between seeing and representation than there is between touching and representation, especially when touch does not also involve sight. The eye can scan or glance as well as gaze upon an object for sure, and the perambulations encouraged within the 'walkways' of the museum do not always allow for easy visual access and a steady view (see Duncan and Wallach 1980). While the connoisseur's gaze may be giving way to the consumer's glance in the museum, (except in the shop where visitors seem to be at their most attentive to objects) it remains true that the eye is privileged over the hand within this space and that encourages different forms of understanding within the viewing audience.

For my purposes, I want to consider how access might be associated with these different concepts of knowing. In other words, I want to look more broadly at how access gets performed and represented in both distal and proximal ways within the museums and to address some of the implications of this. This raises a further set of questions about how we might try and come to understand the body in such a context.

It is not the case that museums inevitably have a distal understanding of these issues and that individual people like Sarah, a more proximal one, relating to their own experiences, understanding and embodiment. Rather, the main question is how these forms of knowledge come together and are deployed either by institutions or by individuals. A person can adopt a distal approach to a question just as readily as institutions can perform knowledge in a proximal way. If institutions do indeed often end up performing a distal view on these issues, we need to recognize the proximal ways in which those who view are often constituted. The issue is how these forms of knowledge get deployed hegemonically and the effects that they 
have subsequently. My argument is that the discourse of access, through which these questions of different forms of knowledge are constituted and played out, is established around a particular deferral that involves the deployment of the practices of accountability and disposal (Hetherington 2000) This is not just something made up of discursive statements found in textual or verbal forms but is expressed quite clearly in the materiality of museum practice. In other words, we can see how distal and proximal forms of knowledge are coconstructed through material forms that act as sites of interface, exchange and translation (Callon 1986, Law 1986, Latour 1993). By analyzing the material in such a way we begin to see how the body gets drawn into these practices. In order to illustrate these issues I will concentrate on a number of facilities for the visually impaired that have been provided by the British Museum in recent years. Here we will move out of the Graeco- Roman gallery and locate ourselves instead in the Duveen gallery that houses one of the most famous and controversial museum exhibits in the world: the Parthenon Frieze and sculptures, also known in their colonial guise as 'the Elgin Marbles.' For it is this exhibit that the British Museum has chosen as its centerpiece for disabled access.

\section{Accountability and Disposal}

I have highlighted the issues of accountability and disposal because I believe them to be important in a museum context to the performance of disabled access and its interpellating effects. I now want to clarify what I take these terms to mean before I go on to demonstrate how they are deployed within the material practices of the museum. In this context accountability can be deconstructed and be shown to mean three things:

i) Accountability: a generic term associated with forms self-recognition of practice associated, in this instance, with disabled access that is open to scrutiny, questioning and audit by others. A particularly distal and often public form of knowledge, accountability in this sense is often associated with standards and best practice and with the manner of their scrutiny, monitoring, measurement and judgement by others. Accountability is particularly associated with the practices of audit. Since the introduction in Britain of the Disability Discrimination Act in 1995 (an act modelled on American legislation only weaker in its application and in its sanctions than the US version) museums have become particularly susceptible to the issue of accountability. The threat of legal action by those who feel they have been discriminated against by a museum means that the latter have become increasingly aware of the need to monitor and review their practices with regard to 'customer needs'. Some museums also seek external advice as a part of this process. Independent, trained access auditors might be asked to produce reports on the quality of the access provision for disabled people within a museum or gallery. In addition, they might seek advice from individuals like Sarah, from focus groups of disabled people, from bodies like the RNIB or other groups like professional associations. Most museums now have published mission statements that include clauses on disabled access and equal opportunities and regularly carry out visitor surveys.

Linked to these processes of audit are funding implications. Grants of large sums of money to improve museum buildings or their collections have become available to the museum sector since the introduction in Britain of a National Lottery in 1994. These often require the completion of detailed formal applications that address issues of access and equal opportunity. An independent access audit has become a de facto requirement before a bid is put in for lottery funding. A bid is unlikely to be successful unless such accountability practices have been carried out and addressed fully in the application. Continual monitoring thereafter is becoming recognized as a necessity and is required as a condition of Museum and Gallery Commission registration.

ii) Account - ability: this second sense of the term implies the ability to 'write' ability into the practices of an institution. While that often means keeping written documents on file it can and does also mean that ability is 'written' into the materials of an institution. In particular, it involves being able to write different forms of dis/ability into the space of the museum. We find such things as the large print sign, leaflets, disabled access symbols, the wheelchair ramp, accessible toilets, hearing loops, audio guides, touch tours, a facility for 
handling collections and so on. These things are all visible indicators that a museum puts on display as evidence of its awareness of disability issues. Many of these facilities are useful to a large number of people, but we should not forget that as signifiers they are slippery and can signify more than just issues of utility. In practice whilst this means providing facilities and services for people with disabilities it also provides a means of writing the museum as accountable.

iii) Account-ability: this third sense of accountability means being able to constitute ability though the practices associated with discourse of demonstrable recognition of the needs of a varied audience. The dis/abled body is constituted though these accounting processes and the material forms in which those processes are expressed. Once it would only have been able bodies that were accounted in such a way. The neo-classical architecture of many of many of the national museums built in the nineteenth century writes (accounts) the body into the museum as able-bodied. Not least through the commonly found steps up to entrance and large monumental staircases to be found once inside. Traditional mahogany display cases have a similar effect on issues of spectatorship within museums. Alongside these architectural and display features one will now often find the ramps and stair lifts which are attempts to write the disabled body into the museum. A Braille sign not only writes disability into the space of the museum, it also writes the body of the visitor into that space as well - it hails them into position so to speak, intepellates them as a subject where previously their subjectivity had been denied or ignored. And while we might not want to adopt the assumptions about ideology and interests that were originally associated with this concept of interpellation (Althusser 1971), we can recognize the potential power effects of this practice.

In sum, legislation, best practice and forms of auditing encourage a distal understanding of the space of the accessible museum and of the embodied subjects that enter it. The subjectivity of 'the visitor', in this case the visually impaired visitor, is constituted ultimately through the first sense of accountability: through action at a distance, through finished, represented forms of knowledge about what is required and how utility can be judged. The practice of doing that however, the techniques, location specific understandings, the materiality of the accessible space and so on, often makes use of the latter two senses in which I use the term account-ability. The issue is that it is the first sense of accountability (that without the hyphen) that is expected to be the final, knowable and monitorable outcome. Its propensity to more distal forms of knowledge has a very particular tendency in this context: accountability and its associated access practices become a way of disposing of the subject of the visually impaired person and their embodied knowledge practices, most notably those associated with the sense of touch, into a representation of an accessible space. Thus, far from being simply a form of 'getting rid of things' disposal has a more precise meaning which concerns issues of placement and the stabilization of social categories, such as able/ disable-bodied.

A common assumption associated with the idea of disposal is that it implies a final act of getting rid of something. On the contrary, disposal is always provisional and in a state of deferral (see Hetherington, 2003). It is also a means through which social issues of membership, inclusion and exclusion can be constituted in practice. Anthropological research on disposal would lead us to this conclusion. From Mary Douglas's classic, if admittedly distal, statement about the 'problem' of disposing of pollution (Douglas 1984), to Michael Thompson's discussion of the recursive role in which rubbish helps to establish the status of objects and the boundaries between them (Thompson 1979) to more recent work on the issue of the impossibility of disposing of meaning (Munro 1995, 1998, Strathern 1999) we can see that disposal is not simply about getting rid of something but rather is about issues of placement through deferring that involves ordering work and is the means to the (always temporary and provisional) stabilization of otherwise fluid categories. In this particular context accounting - accountability in all three senses suggested here - involves the disposal of the unsighted body within the space of the museum as part of the process of stabilizing that space as an accessible one. 
Disposal, then, is not just about rubbish and waste, it is instead concerned with the various acts of moving things about, of arrangement and of the complex ordering work that engages in trying to make representations knowable and stable. In recent anthropological studies of disposal, it is the theme of how societies get rid of unwanted meanings and images, and the ritual ways in which that action becomes meaningful, that has been prominent in discussion (Munro 1995, 1998, Strathern 1999) As Rolland Munro puts it, societies develop 'conduits' for the disposal of unwanted images and meaning and not just the objects of waste (1995). Looking at two different contexts, how disposal is an integral part of the food consumption process and how accountants make use of 'gaps' in their accounts, Munro suggests that dirt can never be fully disposed of. What we do will not simply depend on the choices we make in deciding what to eat or not eat but also through an acknowledgement in advance of the 'conduits for disposal' (Munro 1995:313) that are available to us in which we can dispose of the meaning of what we consume. We do not just produce meaning we also dispose of it too - we keep certain things outside. We can relate this analysis to the questions of access to a museum. Munro recognizes, however, that the conduits of disposal (he cites the fridge as an example in the context of food consumption) do not always work effectively. Such issues of disposal are not just physical though but also symbolic and more broadly cultural, they involve questions of how societies deal with "the haunting presence of exclusion" that is an inevitable part of consumer activities (Munro 1998: 148). And it is the recent emphasis that has been placed on museums making themselves more accessible that has made this exclusion seem like a haunting presence.

Museums used to ignore or even not to acknowledge the possibility of an unsighted visitor. Access has now made that visitor visible - but as a kind of ghost - that now has to be accounted for. The disposal outcome is one placing; acknowledging that we cannot get rid of the consequences of our actions but that we are held accountable by them. This, significantly, is a matter of epistemology just as much as one of ethics; in particular, it is a question of how we account for/are held accountable by that which we have tried to dispose of (Derrida 1994). Disposal in this approach becomes a question of accounting. Accountability, or 'creative accounting', are practices concerned with the way in which we deal with gaps the aporial 'present absence'- within an otherwise seamless (and distal) epistemology that has the ability to haunt unless that gap is accounted for. These gaps may also be seen as fissures through which the Other can leak back in (Munro 1998:145).

Munro recognizes that the representational stability associated with acts of disposal is never ultimately achieved. As 'accountants' we will always find gaps in our accounts/daily life. The question is how we respond to those gaps. The visually impaired visitor is one such present absence or gap that is found in a gallery space of visual culture. The question for museums has come to be one of how that gap is written in, and out, of the museum space. This involves a combination of overt strategies alongside more tacit practices. Above all, then, disposal is concerned with accounting strategies for mobilizing absence and its deployment in the making of a sense of order - and in being able to account for that order (Hetherington and Lee 2000).

Disposal is a way of accounting for the agency of what is absent. We can relate it to the three forms of accountability discussed above and then to museum practice in relation to questions of disabled access. In the first case accountability implies making the conduits of disposal visible and showing that what is visible is fair and proper. A touch tour is a conduit of disposal - it is a way of disposing of the problem of touch within the museum. Limited access is made available through a pre-selected group of objects to a pre-selected group of people (the visually impaired) and the conservational integrity of the rest of the collection, which remains out of touch, is thereby retained. As an example of good practice, the visually impaired person and various interest groups associated with them positively encourage such touch facilities. This becomes visible to all and open to audit when necessary.

In respect of the second sense of accountability we can see that, having provided accessible facilities, museums are able to dispose of the haunting problem of disabled access because they can now write about their access policies and associated practices. These can be stabilized through the handling collections or wheelchair ramps that they have and these can be written about. They can put signs on the door describing the disabled 
facilities they have, can put it in their leaflets, advertise it in published museum guide books, describe it in grant applications and so on. What starts out as a problem - access - ends up as a resource for the museum.

Third, museums fix and stabilize what they understand dis/ability to be through these processes. They dispose of the personal, embodied and proximal experiences of particular individuals by establishing contextually what they want to understand by the categories of disability. As a means of interpellation, disabled facilities write the subjectivity of the disabled into the museum in ways that conform to their overall understanding of access that is established by their representational, and distal, forms of knowledge of it. Most commonly the disabled are interpellated by the wheelchair ramp - this has become a sign of disabled access. The fact that many people with disabilities do not need wheelchairs often goes unnoticed. As well as the ramp, the accessible toilet is the other major signifier. One might suggest, following this logic, that according to the most common museum access practices of account-ability, the disabled are not only in need of a ramp, they are also in need of the toilet. Their messy, leaky bodies (sic) - a problem in a gallery space full of fragile and valuable objects- are constituted as such and disposed of through the accessible toilet, one of the most common disabled facilities found in museums and other public buildings. In this sense the disabled visitor is only accounted for through these features. Their other wants and needs are often ignored in such accounting practices. Their bodies are reduced to the accounts that are inscribed by these facilities. Of course, there are more subtle responses too and some of the recently introduced facilities within the British Museum do illustrate this. Not least the access facilities they have recently opened in the two introductory galleries to the Parthenon Frieze.

\section{Disposing of the Elgin Marbles - Making the Parthenon Frieze Accessible}

The Elgin Marbles have once again become the Parthenon Frieze and Sculptures. Colonial legitimacy has been eroded, even in the British Museum (partially anyway), by post-colonial claims over the rightful ownership and place of museum objects. Eroded but not entirely done away with. The marbles are still in the British Museum rather than back in Greece. But it is in the context of a nation struggling to define itself as multi-cultural and having to respond to what has been called the politics of recognition (Taylor 1992), a recognition and acceptance of identity difference in a non-hierarchical and supporting way, that the British Museum have chosen to respond to questions of access rather than address head on the issue of rightful custodianship. No doubt such museum displays still carry with them many of the cultural assumptions of earlier times associated with the ideas of civilization and empire. These have not been rubbished but they have been disposed of by new interpretive and material ways of addressing the objects in the collection. Such 'classic' displays are now often seen as discriminatory, catering solely for the categories of the unmarked: white, male, western, middle class, heterosexual and able bodied and not recognizing the subaltern position (Spivac 1988). A museum could not continue to receive funding if it did not try and at least qualify such assumptions with recognition of identity difference.

This identity politics has begun to influence writing about museums, training and staff development practices, government policy and funding, the grant application process and is reflected in the diversity of consumer demands being made of museums. While it is not always visible in the galleries of British museums, including the national museums, they have certainly begun to take these issues seriously. However, things like established curatorial authority within an institution's management, career structures, trustee representation and old charters still mean that this is an ongoing and not uncontested process. It is often dealt with in such a way as to make these new claims fit with older ones and with as little disruption as possible. For instance, in the late 1990s the British Museum was ahead of most other museums in Britain in appointing a member of staff with specific responsibility for issues of disabled access. This was part of their account-ability strategy. However, she was a junior member of staff on a short term contract.

More visibly, though, it is around the Parthenon Sculptures that the museum wants to be seen as accounting for disabled access. No doubt, the most obvious access issue 
associated with the marbles presented by this politics of recognition has to do with issues of colonial acquisition and the demands by the Greek government for the return of the marbles to Athens. It is notable therefore, that the museum should have chosen to respond to questions of difference in other ways, sidestepping this more direct and problematic issue of access.

The two newly opened introductory galleries to the Parthenon Frieze demonstrate this. One of these side galleries contains a video on the Parthenon and its history and visitors are encouraged to go and watch it before going on to see the sculptures themselves. It was originally intended that the other gallery would contain casts of sections of the west Frieze of the Parthenon for the reason that the museum does not have the originals from this part of the temple. However, the museum decided to develop the display of casts by making them accessible to the visually impaired visitors in the form of a touch exhibit. So that gallery contains a thermo-plastic scale moulding of a section of the west Frieze with accompanying Braille descriptions and an audio CD guide. The museum has also produced a tactile book called Second Sight of the Parthenon Frieze (Bird, Jenkins and Levi 1998).

Money for the project, indeed for all that was to go into the two new introductory galleries adjacent to the Duveen gallery, came from private American sponsors, Lawrence and Barbara Fleischman. There was a big press launch for invited guests with wide media coverage when the galleries were opened in 1998. The museum went public with this set of developments - it wanted to be seen to be addressing issues of access in a visible way. There are probably a number of reasons for this only one of which was to be seen to be providing access for the visually impaired. The ongoing controversy over the museum having the marbles was probably anther reason and the fact that the museum had recently received a national lottery grant of many millions of pounds to redevelop the central part of the museum around the old British Library reading room was perhaps another. Being accountable is serious business in more ways than one.

For the curatorial staff responsible for the Parthenon sculptures, the problem of how they might be made accessible to the visually impaired was viewed from the outset as an issue of representation. They wanted to improve upon the facilities they had in the other accessible galleries. In part this was prompted by the writing of a book on the sculpture galleries in the museum. When the curator of the Department of Greek and Roman Sculpture, lan Jenkins, proposed this book 1992, he had the idea of producing a tactile version, with simplified raised diagrams that would aid the process of identification for the unsighted. Over a period of time it was decided that this book, along with a plastic moulded section of the frieze and an audio guide, would become part of the new accessible gallery. Possible sponsors were contacted and approved of the idea and decided to put up the money for it. There was also consultation with outside groups, including the Royal National Institute for the Blind (RNIB). The RNIB were able to put the museum in touch with specialists in Italy who had the expertise to translate this idea into practice. Several years of work went into producing these facilities.

The book is unique in its presentation and design. It consists of a series of simplified raised diagrams that show, from various perspectives, to both to the eye and to the trained hand what is depicted in the frieze. There is also an accompanying Braille text, a key of tactile symbols to help with identification and (in the spirit of the British Museum) an additional five hour taped commentary that guides one in using the book. Eye, hand and ear can all be used to understand the representation of the marbles in the 'book'. It has been welcomed by groups such as the RNIB as an example of good access practice for the visually impaired and by those individuals who have handled it (although some do say that the lines could have been raised a little more to give them a clearer definition). ${ }^{4}$ What remains to be said, however, is that this book is foremost an optic representation - a simplified visual depiction of the frieze that can also be touched. The way the book simplifies the carving of the frieze, the use of white space as background for the raised drawings, the use of colour, the conventional book format, all conform to an optical model while also providing the facility for the objects depicted to be touched. It is an optical prosthesis in which the hand can become an eye. Whilst the original objects remain inaccessible to touch, the museum can now deflect any criticism that might be levelled against it on this score by referring critics to this acclaimed alternative. For 
the visually impaired, though, it is not a source of haptic access but an optical prosthesis in which the experienced hand can extend to read the representation.

Around such materials we see different forms of knowledge and work and the different ways that they are used for accounting for the visually impaired visitor to the museum. The museum has acknowledged that visually impaired people want to access the museum and that they need to access it through senses such as hearing and touch as well as in some cases through aided vision. The museum needs to be seen to be providing such facilities it needs to be accountable and those facilities aid in that process.

There is no doubt that the Museum want their exhibits to be more accessible to their visitors than they have been in the past, and that they include visually impaired visitors in this wish. Their good intentions are not in question. What is at issue is the way that such access is routed through distal forms of knowledge and their association with accountability practices and the effects that this has on the experience of the visually impaired visitor.

\section{Conclusion}

I now refer back to the three ways in which I introduced the issue of accountability to make the following general points:

1. The museum's overarching concern is with accountability. The Parthenon marbles are a controversial set of objects and the British Museum has for some time now been on the defensive about its custody of them. Recent claims about alleged damage done to them through conservation practices in the 1930s have not made the issue of custody any easier (St. Clair 1998). The idea of visitors being given greater access through the facilities in the introductory galleries is one way of the museum trying to continue to justify its possession of these artefacts. Alongside the longstanding claims it has always made about legitimate purchase, having world renowned experts on the marbles and their significance in ancient Greece, the museum can now say that it is in keeping with the public mood for museums to shift away from legislative and didactic approaches to culture towards the more interpretive, accessible and indeed spectatorialapproaches. If some of those facilities are especially aimed at a disadvantaged group, the visually impaired, then it can also put itself in the position to address questions about social inclusion. Along with conservation, scholarly enquiry and public education the museum can now add accessibility to its repertoire of practices. Access is not just something that museums can become it is also something that they can do. To do access is to be accountable in a visible and distal way. Not only will visitors approve but so will trustees, funding agencies and governments. So such facilities, as elements of a policy of social inclusion, can mobilize the figure of the visually impaired visitor within the discourse of access precisely because such facilities are in place.

2. It follows that account - ability is a part of this process. Representatives of the British Museum have spoken about these facilities on television and radio. Articles have appeared in newspapers. The tactile book is on sale for $£ 40$ - a rather modest price given both its size and the amount of preparatory work that went into producing it. It and the other facilities can be mentioned in leaflets, posters and any other kind of museum publicity. The access facilities have provided the means for distal forms of representation of the practices involved here. They have the ability to write these facilities into the museum. They can now say that the British Museum signifies accessibility.

3. These practices constitute the visually impaired person and their embodiment through these processes of monitorable practice and their signifying properties. The visually impaired person is now written into the space of the British Museum and is thereby disposed of as a gap. Their embodiment is constituted through the book, the moulded cast section and the audio guide that has been designed for them. Not only what but how they touch is already defined by the materials that have been provided. They have a disciplining effect, in the Foucauldian sense, of ordering the body and its haptic skills in certain ways - ways associated with distal assumptions about what accessibility is (Foucault 1977). The guide to the casts, both in Braille or on $C D$, the tape guide to the book and its conventional page layout all assume that information needs to be provided to aid touch. There is no assumption that touch can simply be for itself - a proximal form of understanding. Above all, that 
information is aimed first at providing a basis for identification - filling in for the kind of identification that would otherwise be done with the eye. That is then supplemented by further information in the form of interpretation. Many visually impaired people welcome this. They take pleasure in the fact that the British Museum has tried to provide facilities for them - it is better than nothing is a commonly heard phrase in interviews I have carried out. Some have said they find handling the book difficult, the lines could have been given clearer definition by raising them more. ${ }^{5}$ What isn't allowed is for people to touch the sculptures themselves.

The subjectivity of visual impairment is now included rather than excluded from the museum but it is included through the interpellating effects of a materiality, a technology that constitutes that subjectivity to fit with the distal ways in which the museum wants to represent these practices. Accounting orders, stabilizes and thereby disposes of a present-absence that the visually impaired visitor to the museum might imply. Touch too is treated as a distal form of knowledge, its proximal sensitivities, not necessarily interested in identification, visualization and representation are ignored and remain unknowable. The tactile aids are used as optical prostheses, there to supplement an impaired and unfinished body and, by implication, aiding an 'impaired' subjectivity. As such, they constitute disability negatively through the idea of non-sight rather than more positively through an understanding of skilled, sensitive touch.

\section{Notes}

1 See Hetherington (2000)

2 Carnegie Trust (1987)

${ }^{3}$ For a discussion of topological complexity see Mol and Law (1994).

${ }^{4}$ Interviews with LC, 01.

5 Interviews with LC, GS.

\section{Acknowledgements}

I would like to thank Gordon Fyfe for his helpful comments on an earlier version of this paper.

\section{References}

Althusser, L. (1971) Lenin and Philosophy, London: New Left Books

Bird, S., I. Jenkins and F. Levi (1998) Second Sight of the Parthenon Frieze, London: The British Museum.

Callon, M. (1986) 'Some Elements of a Sociology of Translation: Domestication of the Scallops and the Fishermen of St Brieuc Bay, 196-233 in J. Law (ed.) Power, Action and Belief, London: Routledge and Kegan Paul.

Carnegie United Kingdom Trust (1985) Arts and Disabled People: The Attenborough Report, London: Bedford Square Press.

Carnegie Review Council (1988) After Attenborough, London: Bedford Square Press.

Cooper, R. and J. Law (1995) 'Organisation: Distal and Proximal Views' in S. Bachrach et al. (eds) Research in the Sociology of Organisations, Greenwich Conn.: JAI Press.

Derrida, J. (1994) Spectres of Marx, New York: Routledge

Douglas, M. (1984) Purity and Danger, London: Ark/Routledge

Duncan, C. and Wallach, A. (1980) 'The Universal Survey Museum', Art History, Vol. 3 (4) 447469. 
Foucault, M. (1977) Discipline and Punish, Harmondsworth: Penguin.

Haraway, D. (1991) 'Situated Knowledges: the Science Question in feminism and the Privilege of Partial perspective', 183-201 in Simians, Cyborgs and Women, London: Free Association Books.

Hetherington, K. (2000) 'Museums and the Visually Impaired: The Spatial Politics of Access', The Sociological Review, 48 (3): 444-463.

Hetherington, K. (2002) 'The Unsightly: Visual Impairment, Touch and the Parthenon Frieze', Theory, Culture and Society, Vol. 19(5/6):187-205.

Hetherington, K. (2003) 'Secondhandedness: Consumption, Disposal and Absent-Presence' Environment and Planning D: Society and Space - Forthcoming

Hetherington, K. and N. Lee (2000) 'Social Order and the Blank Figure', Environment and Planning D: Society and Space, Vol. 18 (2): 169-184.

Jospovici, G. (1996) Touch, New Haven: Yale University Press.

Latour, B. (1993) We Have Never Been Modern, London: Harvester/Wheatsheaf

Law, J. (1986) 'On the Methods of Long Distance Control: Vessels, Navigation and the Portuguese Route to India', in J. Law (ed.) Power, Action and Belief, London: Routledge and Kegan Paul.

Lyotard, J-F, (1996) 'Les Immateriaux' in R. Greenberg, B. Ferguson and S. Nairne (eds) Thinking About Exhibitions, London: Routledge, 159-173

Mol, A-M, and J. Law (1994) 'Regions, Networks and Fluids: Anaemia and Social Topology, Social Studies of Science, 26: 641-671.

Munro, R. (1995) 'Disposal of the Meal' in D. Marshall (ed.) Food Choice and the Consumer, London: Blackie Academic, 313-25

Munro, R. (1998) 'Disposal of the X gap:The Production and Consumption of Accounting Research and Practical Accounting Systems', Advances in Public Interest Accounting, 7: $139-59$

St. Clair, W. (1998) Lord Elgin and the Marbles, Oxford:Oxford University Press.

Spivak, G. (1988) 'Can the Subaltern Speak?' in C. Nelson and L. Grossberg (eds) Marxism and the Interpretation of Culture, Urbana: University of Illinois Press, 272-313

Strathern, M. (1999) 'The Aesthetics of Substance' in Property, Substance and Effect, London: Athlone, 45-63

Taylor, C. (1992) 'The Politics of Recognition' C. Taylor et al. (eds) Multiculturalism, Princeton: Princeton University Press, 25-73

Thompson, M. (1979) Rubbish Theory, Oxford: Oxford University Press.

Turner, B. (1992) 'Reflections on the Epistemology of the Hand' in Regulating Bodies, London: Routledge, 99-121. 
* Kevin Hetherington is Reader in Sociology at Lancaster University and has previously held posts at the Universities of Brunel and Keele. His interests include space, identity, materiality and access to public culture. He has written extensively on the subjects of marginality, social movements, consumption and museums. His recent books include New Age Travellers (2000) London: Cassell and Expressions of Identity (1998) London:Sage. 